\title{
Testing Linearity in Cointegrating Smooth Transition Regressions*
}

\author{
In Choi ${ }^{\dagger}$ and Pentti Saikkonen ${ }^{\ddagger}$
}

First Draft: December, 2001

\begin{abstract}
This paper develops statistical tests that can be used to test linearity in a general cointegrating smooth transition regression model. These tests extend previous similar tests by considering $I(1)$ regressors instead of stationary or mixing regressors. As is typical in cointegrating regressions, the regressors and errors of the model can also be serially and contemporaneously correlated. In order to allow for this feature, an endogeneity correction based on a leads-andlags approach is employed. Additionally, the model of this paper has more general transition mechanisms than in previous studies. The proposed tests are very simple to use because ordinary least squares techniques and standard chisquare limiting distributions apply. Simulation experiments indicate that the tests have reasonable finite sample properties. Empirical applications to a U.S. money demand function illustrate the practical usefulness of the tests.
\end{abstract}

\section{Introduction}

Since its introduction in the 1980s, the theory of cointegration has undergone considerable development and become a central part of modern time series econometrics. Various econometric and statistical methods have been developed for the analysis of cointegrated time series and many of them are now routinely applied in empirical studies. However, most of the methods presently available assume that the cointegrating relations are linear, which according to economic theory, need not be the case. For instance, economic theories for money demand do not require the money demand function be linear (see, e.g., Baba, Hendry and Starr (1992), Baumol (1952) and Tobin (1956)), although linearity has been assumed in most empirical studies. Also, the relationship between exchange rates and fundamentals may be nonlinear as

\footnotetext{
*The second author thanks the Yrjö Jahnsson Foundation for financial support.

${ }^{\dagger}$ Department of Economics, Hong Kong University of Science and Technology, Clear Water Bay, Kowloon, Hong Kong. E-mail: inchoi@ust.hk

${ }^{\ddagger}$ Department of Statistics, P.O. Box 54 (Unioninkatu 37), FIN-00014 University of Helsinki, Finland. Email: pentti.saikkonen@helsinki.fi
} 
in Krugman's (1991) target zone model, though previous studies using the first differences of the exchange rates and fundamentals are not supportive of the nonlinear relationship (see, e.g., Meese and Rose (1990, 1991)). Being able to investigate the possibility of a nonlinear cointegrating relation is therefore of interest, especially if an estimated linear cointegrating relation is found to be far from that predicted by economic theory.

The purpose of this paper is to develop test procedures that can be used to test the linearity of a cointegrating relation in the context of a nonlinear cointegrating smooth transition regression (STR) model. Our test procedures are based on the approach previously used for stationary models by Luukkonen, Saikkonen and Teräsvirta (1988) and Granger and Teräsvirta (1993) amongst others (for further references, see Teräsvirta (1998) and van Dijk, Teräsvirta and Franses (2000)). An advantage of this approach is that the resulting tests are very simple to use. Computations can be carried out by ordinary least squares (OLS) and a standard chi-square criterion can be used to obtain asymptotically valid tests.

Although our tests have the same basis as previous linearity tests developed for STR models, the fact that we are working with a cointegrating regression brings about notable new features to the testing problem. Due to the cointegration, we have to relax previous assumptions of stationary or mixing regressors and allow for nonstationary $I(1)$ regressors. Unlike in the previous literature, we shall not assume that the regressors are exogenous in any sense. Instead, we follow the common practice in cointegrating regressions and permit both serial and contemporaneous correlations between the regressors and error term of the model. In order to allow for this feature, we use the leads-and-lags approach proposed by Saikkonen (1991), Phillips and Loretan (1991) and Stock and Watson (1993) for linear cointegrating regressions and Saikkonen and Choi (2000) for somewhat more general cointegrating STR regressions than those considered in this paper. As with cointegrating regressions in general, the error term of our model can be serially correlated. A further point which makes our model more general than previous stationary STR models is that it may contain several transition functions and more than a single transition variable.

The rest of the paper is organized as follows. Section 2 introduces the model, hypotheses and assumptions. Section 3 develops the linearity tests. Section 4 reports simulation results of the finite sample properties of the developed tests and Section 5 applies them to a U.S. money demand function. Section 6 concludes.

\section{The Model, Hypotheses and Assumptions}

Consider the cointegrating STR model

$$
y_{t}=\mu+\sum_{j=1}^{q} \nu_{j} g_{j}\left(\mathbf{z}_{j t}\right)+\alpha^{\prime} x_{t}+\sum_{j=1}^{q} \beta_{j}^{\prime} x_{t} g_{j}\left(\mathbf{z}_{j t}\right)+u_{t}, \quad t=1,2, \ldots, T,
$$

where $x_{t}=\left[x_{1 t}, \ldots, x_{p t}\right]^{\prime}$ is a $p$-dimensional $I(1)$ process, $u_{t}$ is a zero-mean stationary error term, and the components of the vector $\mathbf{z}_{j t}=\left[z_{j 1 t}, \ldots, z_{j m_{j}}\right]^{\prime}$ are given by

$$
z_{j i t}=\gamma_{j i}\left(x_{i t}-c_{j i}\right), \gamma_{j i} \neq 0, \quad i=1, \ldots, m_{j} .
$$


Furthermore, $g_{j}\left(\mathbf{z}_{j t}\right)$ is a smooth, real-valued transition function of the process $x_{t}$ and the scalar parameters $\gamma_{j 1}, \ldots, \gamma_{j m_{j}}, c_{j 1}, \ldots, c_{j m_{j}}$. Of the other parameters of the model, $\mu$ and $\nu_{j}$ are scalars and $\alpha$ and $\beta_{j}$ are $p \times 1$ vectors.

Model (1) could be extended by including additional $I(1)$ regressors that are not affected by the transition functions. For simplicity, this extension is not made explicit in this paper. ${ }^{1}$ The nonlinear nature of the model is determined by the transition functions $g_{j}\left(\mathbf{z}_{j t}\right)$ whose number may be larger than one and each of which may depend on different components of the process $x_{t} \cdot{ }^{2}$

We are interested in testing the null hypothesis that model (1) reduces to a conventional linear cointegrating regression. Thus, the null hypothesis of interest is

$$
H_{0}: \nu_{j}=0 \text { and } \beta_{j}=0 \text { for all } j=1, \ldots, q .
$$

The alternative simply states that the null hypothesis is not true.

STR models have been used to describe economic relations that change smoothly depending on the location of some economic variables. In model (1), an appropriate choice of the transition function $g_{j}\left(\mathbf{z}_{j t}\right)$ allows the relationship between $x_{t}$ and $y_{t}$ to change depending on where the first $m_{j}$ components of the vector $x_{t}$ are located relative to the parameters $c_{j 1}, \ldots, c_{j m_{j}}$. The smoothness of the change is determined by the parameters $\gamma_{j i}$. Examples will be given shortly. Further examples and discussions on the STR model can be found in Granger and Teräsvirta (1993), Teräsvirta (1998), and van Dijk et al. (2000), although these authors do not explicitly consider the case of $I(1)$ processes.

As for the transition function $g_{j}\left(\mathbf{z}_{j}\right)\left(\mathbf{z}_{j}=\left[z_{j 1}, \ldots, z_{j m_{j}}\right]^{\prime}\right)$, we assume

Assumption 1 (i) $g_{j}(0)=0$ for all $j$.

(ii) For all $j$, the function $g_{j}\left(\mathbf{z}_{j}\right)$ is three times differentiable in an open ball in $\mathbb{R}^{m_{j}}$ with center 0 and radius $r_{j}\left(r_{j}>0\right)$.

(iii) For all $j, \frac{\partial g_{j}\left(\mathbf{z}_{j}\right)}{\partial z_{j i}} \mid \mathbf{z}=0$ for at least one $i$.

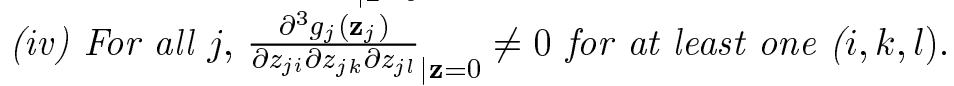

The most commonly used transition functions satisfy Assumption 1, as illustrated by the following examples and the examples given in the aforementioned references.

Example $1 p=q=m_{1}=1$

$$
g_{1}\left(\mathbf{z}_{1 t}\right)=\frac{1}{1+e^{-\gamma_{11}\left(x_{1 t}-c_{11}\right)}}-\frac{1}{2}, \quad \gamma_{11}>0 .
$$

\footnotetext{
${ }^{1}$ When there are additional $I(1)$ variables, we add the variables in levels and their differences in leads-and-lags to models (11) and (13). Asymptotic distributions of our tests are not affected by this.

${ }^{2}$ Variables other than $x_{1 t}, \ldots, x_{p t}$ may enter the transition function. Extending our tests to this case is straightforward.
} 
In this example, the transition function is a logistic function which makes the regression coefficient for $x_{1 t}$ vary smoothly between $\alpha_{1}-\frac{1}{2} \beta_{11}$ and $\alpha_{1}+\frac{1}{2} \beta_{11}$ where $\alpha_{1}$ and $\beta_{11}$ are the first components of the vectors $\alpha$ and $\beta_{1}$, respectively. When the value of the regressor $x_{1 t}$ is sufficiently far below the value of the parameter $c_{11}$ the regression coefficient takes a value close to $\alpha_{1}-\frac{1}{2} \beta_{11}$; and when the value of the regressor $x_{1 t}$ increases and exceeds the value of the parameter $c_{11}$ the value of the regression coefficient changes and approaches $\alpha_{1}+\frac{1}{2} \beta_{11}$. The intercept term undergoes similar changes.

Example $2 p=1, q=2, m_{1}=m_{2}=1$

$$
\begin{aligned}
& g_{1}\left(\mathbf{z}_{1 t}\right)=\frac{1}{1+e^{-\gamma_{11}\left(x_{1 t}-c_{11}\right)}}-\frac{1}{2}, \quad \gamma_{11}>0 \\
& g_{2}\left(\mathbf{z}_{2 t}\right)=\frac{1}{1+e^{-\gamma_{21}\left(x_{1 t}-c_{21}\right)}}-\frac{1}{2}, \quad \gamma_{21}>0 .
\end{aligned}
$$

If we here assume that $c_{21}>c_{11}$, then the coefficient for $x_{1 t}$ changes slowly from $\alpha_{1}-\frac{1}{2} \beta_{11}-\frac{1}{2} \beta_{21}$ via $\alpha_{1}+\frac{1}{2} \beta_{11}-\frac{1}{2} \beta_{21}$ to $\alpha_{1}+\frac{1}{2} \beta_{11}+\frac{1}{2} \beta_{21}$ for increasing values of $x_{1 t}$. Thus, there are basically three data regimes in this example. A similar interpretation applies when $c_{11}>c_{21}$.

Example $3 p=2, q=1, m_{1}=2$

$$
g_{1}\left(\mathbf{z}_{1 t}\right)=\frac{1}{1+e^{-\gamma_{11}\left(x_{1 t}-c_{11}\right)}} \times \frac{1}{1+e^{-\gamma_{12}\left(x_{2 t}-c_{12}\right)}}-\frac{1}{4}, \quad \gamma_{11}>0, \gamma_{12}>0 .
$$

This example differs from the previous ones in that there are two transition variables $x_{1 t}$ and $x_{2 t}$. Only when the values of both $x_{1 t}$ and $x_{2 t}$ are greater than $c_{11}$ and $c_{12}$, respectively, does the coefficient vector of $x_{t}$ become $\alpha+\frac{3}{4} \beta_{1}$. Otherwise, it is $\alpha-\frac{1}{4} \beta_{1}$. So there are two data regimes characterized by $x_{1 t}$ and $x_{2 t}$.

Example $4 p=2, q=1, m_{1}=2$

$$
g_{1}\left(\mathbf{z}_{1 t}\right)=\frac{1}{1+e^{-\gamma_{11}\left(x_{1 t}-c_{11}\right)}}-\frac{1}{1+e^{-\gamma_{12}\left(x_{2 t}-c_{12}\right)}}, \quad \gamma_{11}>0, \gamma_{12}>0 .
$$

There are three data regimes in this example. When the values of both $x_{1 t}$ and $x_{2 t}$ are either large or small simultaneously, the transition function takes the value 0 . Otherwise, it takes the value either 1 or -1 .

We shall now discuss assumptions required for model (1). As already mentioned, we assume

\section{Assumption 2}

$$
x_{t}=x_{t-1}+v_{t}, \quad t=1,2, \ldots,
$$

where $v_{t}$ is a zero-mean stationary process and the initial value $x_{0}$ may be any random variable with the property $E\left\|x_{0}\right\|^{2}<\infty$. 
Moreover, it will be convenient to assume that the $(p+1)$-dimensional process $w_{t}=\left[u_{t} v_{t}^{\prime}\right]^{\prime}$ satisfies the following assumption employed by Hansen (1992) in a somewhat weaker form.

Assumption 3 For some $r>4, w_{t}=\left[\begin{array}{ll}u_{t} & v_{t}^{\prime}\end{array}\right]^{\prime}$ is a stationary, zero-mean, strong mixing sequence with mixing coefficients of size $-4 r /(r-4)$ and $E\left\|w_{t}\right\|^{r}<\infty$.

Assumption 3 is fairly general. It covers a variety of weakly dependent processes and implies that an invariance principle applies to partial sums formed of the process $w_{t}$ (see Hansen, 1992, the proof of Theorem 3.1). It also permits the cointegrated system defined by (1) and (5) to have nonlinear short-run dynamics, which is convenient when the cointegrating regression is nonlinear.

As discussed in Saikkonen and Choi (2000), Assumption 3 implies that the process $w_{t}$ has a continuous spectral density matrix $f_{w w}(\lambda)$ that we assume to satisfy

Assumption 4 The spectral density matrix $f_{w w}(\lambda)$ is bounded away from zero or the matrix $f_{w w}(\lambda)-\varepsilon I_{p+1}$ is positive semidefinite for some $\varepsilon>0$.

Assumption 4 specialized to the case $\lambda=0$ implies that the components of the $I$ (1) process $x_{t}$ are not cointegrated. Conformably to the partition of the process $w_{t}$, we write $f_{w w}(\lambda)=\left[f_{a b}(\lambda)\right]$ where $a, b \in\{u, v\}$. The long-run covariance matrix of the process $w_{t}$ is defined by $\Omega=2 \pi f_{w w}(0)$ and partitioned conformably with the other partitions as

$$
\Omega=\left[\begin{array}{ll}
\omega_{u}^{2} & \omega_{u v} \\
\omega_{v u} & \Omega_{v v}
\end{array}\right]
$$

\section{Test Procedures}

This section develops tests for the linearity hypothesis (2) against the general cointegrating STR model (1). This testing problem is nonstandard because the nuisance parameters $\gamma_{j i}$ and $c_{j i}$ are not identified under the null hypothesis. This can be seen from equation (1) because, under the null hypothesis, the transition functions $g_{j}\left(\mathbf{z}_{j t}\right)$ and, consequently, the parameters $\gamma_{j i}$ and $c_{j i}$ can take any values without any effect on the model specification.

There has recently been a great interest in obtaining test procedures when a nuisance parameter is not identified under the null hypothesis and significant progress has been made by Andrews (1993), Andrews and Ploberger (1994) and Hansen (1996). However, instead of following the approach of these authors, we proceed as in Luukkonen et al. (1988) and obtain very simple tests by replacing the transition functions $g_{j}\left(\mathbf{z}_{j t}\right)$ by Taylor series approximations. This approach, which leads to standard tests, has recently been used by several authors (see Granger and Teräsvirta (1993), Teräsvirta (1998), van Dijk et al. (2000), and the references therein). However, as pointed out in the introduction, there are important differences between our model and those employed by previous authors.

As was done in Luukkonen et al. (1988), we consider two tests referred to as the first order test and third order test. Both of these tests are similar to Lagrange 
Multiplier (LM) tests in that they only require the estimation of the model under the null hypothesis of linearity. The simplicity of these tests stems from this fact because under this null hypothesis OLS can be used for parameter estimation.

\subsection{First-order test}

The first-order Taylor series approximation of the function $g_{j}\left(\mathbf{z}_{j t}\right)$ around the origin is given by

$$
\sum_{i=1}^{m_{j}} b_{j i} \gamma_{j i}\left(x_{i t}-c_{j i}\right)
$$

where $b_{j i}=\frac{\partial g_{j}(\mathbf{z})}{\partial z_{j i}}{ }_{\mid \mathbf{z}=0}$. Substituting (6) for $g_{j}\left(\mathbf{z}_{j t}\right)$ in model (1) yields

$$
\begin{aligned}
y_{t} & =\mu+\sum_{j=1}^{q} \nu_{j} \sum_{i=1}^{m_{j}} b_{j i} \gamma_{j i}\left(x_{i t}-c_{j i}\right)+\alpha^{\prime} x_{t}+\sum_{j=1}^{q} \beta_{j}^{\prime} x_{t} \sum_{i=1}^{m_{j}} b_{j i} \gamma_{j i}\left(x_{i t}-c_{j i}\right)+\eta_{t} \\
& =\phi+\rho^{\prime} x_{t}+\sum_{k=i}^{p} \sum_{i=1}^{m} \theta_{k i} x_{k t} x_{i t}+\eta_{t},
\end{aligned}
$$

where $m=\max \left\{m_{1}, \ldots, m_{q}\right\}$ and the parameters $\phi$ (scalar), $\rho=\left[\rho_{1}, \ldots, \rho_{p}\right]^{\prime}$ and $\theta_{k i}$ (scalar) are defined implicitly. The error term $\eta_{t}$ is the sum of $u_{t}$ in model (1) and the approximation error. Under the null hypothesis (2), the approximation error vanishes and, consequently, $\eta_{t}=u_{t}$. The idea is to test the original null hypothesis (2) by testing the null hypothesis

$$
H_{0}^{\prime}: \theta_{k i}=0 \quad(i=1, \ldots, m ; k=i, \ldots, p)
$$

in the auxiliary regression model (7).

In order to motivate this test procedure, suppose that the error term $u_{t}$ in model (1) is Gaussian white noise and that the regressor vector $x_{t}$ is strictly exogenous. Then, instead of the null hypothesis (2), the linearity of the STR model (1) can be tested by testing the null hypothesis $H_{0}^{\prime \prime}: \gamma_{j i}=0\left(i=1, \ldots, m_{j} ; j=1, \ldots, q\right)$. Under this null hypothesis the nuisance parameters $\nu_{j}$ and $\beta_{j}(j=1, \ldots, q)$ are not identified. However, a test can be obtained in the same way as in Granger and Teräsvirta (1993, p. 71-72). The first step is to derive a LM test for the null hypothesis $H_{0}^{\prime \prime}$ by assuming that the values of the unidentified nuisance parameters $\nu_{j}$ and $\beta_{j}(j=1, \ldots, q)$ are fixed. This yields a test statistic that depends on the values given for the unidentified nuisance parameters. A standard approach in a case like this is to take the supremum of the obtained test statistic over the values of the nuisance parameters. It is easy to see that the test statistic obtained in this way is exactly the same as that obtained by using the standard LM test for testing the null hypothesis (8) in the auxiliary regression model (7) (cf. Granger and Teräsvirta (1993, p. 71-72)). Thus, in this special case the auxiliary regression model (7) and the related null hypothesis (8) can be used to obtain a 'supLM' test for the original testing problem.

Motivated by the above discussion, we consider the LM test for the null hypothesis (8) in the auxiliary regression model (7) even in the general case where the simplified 
assumptions used above are not satisfied. However, an endogeneity correction is needed because the regressors are allowed to be correlated with error term. Our endogeneity correction is based on the leads-and-lags approach recently studied by Saikkonen and Choi (2000) in the context of a cointegrating STR regression model somewhat more general than (1). Under Assumptions 3 and 4, we can express the error term $u_{t}$ in (1) as

$$
u_{t}=\sum_{j=-\infty}^{\infty} \pi_{j}^{\prime} v_{t-j}+e_{t}
$$

where $e_{t}$ is a zero-mean stationary process such that $E e_{t} v_{t-j}^{\prime}=0$ for all $j=0, \pm 1, \ldots$, and

$$
\sum_{j=-\infty}^{\infty}\left\|\pi_{j}\right\|<\infty
$$

(see Saikkonen (1991) and Saikkonen and Choi (2000)). Expressions for the spectral density function and long-run variance of the process $e_{t}$ can be obtained from the wellknown formulas $f_{e e}(\lambda)=f_{u u}(\lambda)-f_{u v}(\lambda) f_{v v}^{-1}(\lambda) f_{v u}(\lambda)$ and $\omega_{e}^{2}=\omega_{u}^{2}-\omega_{u v} \Omega_{v v}^{-1} \omega_{v u}$, respectively.

Now, recall that the error term $\eta_{t}$ in (7) is the sum of $u_{t}$ and the approximation error due to the use of the Taylor series approximation (6). Using equations (5) and (9), we can thus write the auxiliary regression model (7) as

$$
\begin{aligned}
y_{t} & =\phi+\rho^{\prime} x_{t}+\sum_{k=i}^{p} \sum_{i=1}^{m} \theta_{k i} x_{k t} x_{i t}+\sum_{j=-K}^{K} \pi_{j}^{\prime} \Delta x_{t-j}+\eta_{K t}, \\
& =\phi+\rho^{\prime} x_{t}+\zeta^{\prime} n_{t}+\sum_{j=-K}^{K} \pi_{j}^{\prime} \Delta x_{t-j}+\eta_{K t}, \quad t=K+1, \ldots, T-K,
\end{aligned}
$$

where $\Delta$ signifies the difference operator, $\zeta=\left[\theta_{11}, \ldots, \theta_{p m}\right]^{\prime}, n_{t}=\left[x_{1 t}^{2}, \ldots, x_{p t} x_{m t}\right]^{\prime}$, and the error term $\eta_{K t}$ is the sum of the above mentioned Taylor series approximation error and

$$
e_{t}+\sum_{|j|>K} \pi_{j}^{\prime} v_{t-j} \stackrel{\text { def }}{=} e_{K t} .
$$

The augmented auxiliary regression model (11) will be used to test the null hypothesis (8) or, equivalently, $\zeta=0$. In order to eliminate errors caused by truncating the infinite sum in (9), we have to consider asymptotics in which the integer $K$ tends to infinity with $T$ at a suitable rate. To this end, we follow Saikkonen (1991) and Saikkonen and Choi (2000) and assume

Assumption $5 K=o\left(T^{3}\right)$ and $T^{1 / 2} \sum_{|j|>K}\left\|\pi_{j}\right\| \rightarrow 0$ as $T \rightarrow \infty$.

Let $M$ be the moment matrix for the auxiliary regression model $(11)$ and $\left(M^{-1}\right)_{n n}$ the block of the matrix $M^{-1}$ corresponding to $n_{t}$. Then the LM test for the null hypothesis (8) is defined as

$$
\mathcal{T}_{1}=\hat{\zeta}^{\prime}\left[\tilde{\omega}_{e}^{2}\left(M^{-1}\right)_{n n}\right]^{-1} \hat{\zeta}
$$


where $\hat{\zeta}$ is the OLS estimator of $\zeta$ in (11) and $\tilde{\omega}_{e}^{2}$ is a standard long-run variance estimator based on the residuals of the corresponding restricted OLS estimation. In other words, $\tilde{\omega}_{e}^{2}$ is obtained from $\tilde{u}_{t}=y_{t}-\tilde{\phi}-\tilde{\rho}^{\prime} x_{t}-\sum_{j=-K}^{K} \tilde{\pi}_{j}^{\prime} \Delta x_{t-j}$ where $\tilde{\phi}, \tilde{\rho}$ and $\tilde{\pi}_{j}$ are the OLS estimators of the coefficients $\phi, \rho$ and $\pi_{j}$, respectively, in the auxiliary regression model (11) constrained by $\zeta=0$.

Since the null hypothesis implies that $\eta_{K t}=e_{K t}$ in (11) the limiting null distribution of test statistic $\mathcal{T}_{1}$ can be inferred from the results of Saikkonen and Choi (2000), which apply when Assumptions 2, 3, 4 and 5 are satisfied. ${ }^{3}$ These results can be used to show that, under the null hypothesis, standard methods used to construct the long-run variance estimator $\tilde{\omega}_{e}^{2}$ (e.g., Andrews (1991)) are consistent, and furthermore, that $\left[\tilde{\omega}_{e}^{2}\left(M^{-1}\right)_{n n}\right]^{-1 / 2} \hat{\zeta}$ has a standard normal limiting distribution. ${ }^{4}$ This implies that the limiting null distribution of test statistic $\mathcal{T}_{1}$ is given by

$$
\mathcal{T}_{1} \stackrel{d}{\longrightarrow} \chi^{2}\left(\frac{(2 p-m+1) m}{2}\right) \text { as } T \rightarrow \infty .
$$

Thus, we have shown that a standard chi-square criterion can be used to construct an asymptotic test for the linearity hypothesis.

\subsection{Third-order test}

In equations (7) and (11), the parameters $\theta_{k i}$ are not functions of the parameters $\nu_{j}$, which only affect the parameters $\phi$ and $\rho$. Because the parameters $\nu_{j}$ cannot be separated from $\phi$ and $\rho$, test statistic $\mathcal{T}_{1}$ may have low power when the values of $\nu_{j}$ are large and the elements of $\beta_{j}$ are small in absolute value. To remedy this problem, we follow Luukkonen et al. (1988) and consider a test based on the third-order Taylor series approximation of $g_{j}\left(\mathbf{z}_{j t}\right)$.

The third-order Taylor series approximation of the function $g_{j}\left(\mathbf{z}_{j t}\right)$ around the origin can be written as

$$
\begin{aligned}
& \sum_{i=1}^{m_{j}} b_{j i} \gamma_{j i}\left(x_{i t}-c_{j i}\right)+\sum_{k=i}^{m_{j}} \sum_{i=1}^{m_{j}} d_{j k i} \gamma_{j i} \gamma_{j k}\left(x_{i t}-c_{j i}\right)\left(x_{k t}-c_{j k}\right) \\
& +\sum_{l=k}^{m_{j}} \sum_{k=i}^{m_{j}} \sum_{i=1}^{m_{j}} h_{j l k i} \gamma_{j i} \gamma_{j k} \gamma_{j l}\left(x_{i t}-c_{j i}\right)\left(x_{k t}-c_{j k}\right)\left(x_{l t}-c_{j l}\right),
\end{aligned}
$$

where $b_{j i}, d_{j k i}$ and $h_{j l k i}$ are constants determined by partial derivatives of $g_{j}\left(\mathbf{z}_{j t}\right)$ at the origin. ${ }^{5}$ Because the motivation for using the third-order approximation is to improve the power of test statistic $\mathcal{T}_{1}$ under $\nu_{j} \neq 0$, we use the approximate relation

\footnotetext{
${ }^{3}$ The asymptotic results of Saikkonen and Choi (2000) were derived by using the so-called triangular array asymptotics. However, when the nonlinearity is defined by a homogeneous function, as is the case in (11), there is no real difference between the triangular array asymptotics and usual asymptotics.

${ }^{4}$ Note that $T \hat{\zeta}$ has a mixture normal distribution with the variance-covariance matrix that is the weak limit of $\omega_{e}^{2}\left(\left(M / T^{2}\right)^{-1}\right)_{n n}$.

${ }^{5}$ The second-order derivatives of the transition functions in Examples 1,2 and 4 take the value zero at the origin, but that of the transition function in Example 3 is not zero at the origin.
} 
(12) only for the transition of the intercept term and continue to use the relation (6) for the transition involving the regressors. The resulting auxiliary regression model that corresponds to model (11) is then

$$
\begin{aligned}
y_{t}= & \mu+\sum_{j=1}^{q} \nu_{j}\left[\begin{array}{c}
\sum_{i=1}^{m_{j}} b_{j i} \gamma_{j i}\left(x_{i t}-c_{j i}\right)+\sum_{k=i}^{m_{j}} \sum_{i=1}^{m_{j}} d_{j k i} \gamma_{j i} \gamma_{j k}\left(x_{i t}-c_{j i}\right)\left(x_{k t}-c_{j k}\right) \\
+\sum_{l=k}^{m_{j}} \sum_{k=i}^{m_{j}} \sum_{i=1}^{m_{j}} h_{j l k i} \gamma_{j i} \gamma_{j k} \gamma_{j l}\left(x_{i t}-c_{j i}\right)\left(x_{k t}-c_{j k}\right)\left(x_{l t}-c_{j l}\right)
\end{array}\right] \\
& +\alpha^{\prime} x_{t}+\sum_{j=1}^{q} \beta_{j}^{\prime} x_{t} \sum_{i=1}^{m_{j}} b_{j i} \gamma_{j i}\left(x_{i t}-c_{j i}\right)+\sum_{j=-K}^{K} \pi_{j}^{\prime} \Delta x_{t-j}+\eta_{K t}^{*} \\
= & \psi+\xi^{\prime} x_{t}+\sum_{k=i}^{p} \sum_{i=1}^{m} \varphi_{i k} x_{k t} x_{i t}+\sum_{l=k}^{m} \sum_{k=i}^{m} \sum_{i=1}^{m} \lambda_{l k i} x_{i t} x_{k t} x_{l t}+\sum_{j=-K}^{K} \pi_{j}^{\prime} \Delta x_{t-j}+\eta_{K t}^{*} \\
= & \psi+\xi^{\prime} x_{t}+\varsigma^{\prime} h_{t}+\sum_{j=-K}^{K} \pi_{j}^{\prime} \Delta x_{t-j}+\eta_{K t}^{*} .
\end{aligned}
$$

Here $\varsigma=\left[\varphi_{11}, \ldots, \varphi_{m p}, \lambda_{111}, \ldots, \lambda_{m m m}\right]^{\prime}, h_{t}=\left[x_{1 t}^{2}, \ldots, x_{p t} x_{m t}, x_{1 t}^{3}, \ldots, x_{m t}^{3}\right]^{\prime}$ and, as before, $m=\max \left\{m_{1}, \ldots, m_{q}\right\}$. Moreover, the $p \times 1$ parameter vector $\xi$ and the scalar parameters $\varphi_{i k}, \lambda_{l k i}$ and $\psi$ are defined implicitly.

Instead of the original null hypothesis (2), the idea is now to test the null hypothesis

$$
H_{0}^{\prime \prime \prime}: \varsigma=0
$$

in the auxiliary regression model (13) using the LM test. In order to introduce the test statistic, let $\bar{M}$ be the moment matrix for the auxiliary regression model (13) and $\left(\bar{M}^{-1}\right)_{h h}$ the block of the matrix $\bar{M}^{-1}$ corresponding to $h_{t}$. Furthermore, let $\hat{\varsigma}$ be the OLS estimator of $\varsigma$ in (13) and $\tilde{\omega}_{e}^{2}$ a standard long-run variance estimator based on the residuals of the corresponding OLS estimation constrained by $\varsigma=0$. Then our test statistic is defined as

$$
\mathcal{T}_{2}=\hat{\varsigma}^{\prime}\left[\tilde{\omega}_{e}^{2}\left(\bar{M}^{-1}\right)_{h h}\right]^{-1} \hat{\varsigma} .
$$

In the same way as in the case of test statistic $\mathcal{T}_{1}$, we can use the results of Saikkonen and Choi (2000) to show that, when Assumptions 2, 3, 4 and 5 hold, the limiting null distribution of test statistic $\mathcal{T}_{2}$ is given by

$$
\mathcal{T}_{2} \stackrel{d}{\longrightarrow} \chi^{2}\left(\frac{(2 p-m+1) m}{2}+\frac{m(m+1)(m+2)}{6}\right) \text { as } T \rightarrow \infty .
$$

Thus, compared to the limiting distribution of test statistic $\mathcal{T}_{1}$, the number of degrees of freedom has increased by the number of additional restrictions included in the auxiliary null hypothesis.

\section{Simulation}

This section reports simulation results of the empirical size and power of test statistics $\mathcal{T}_{1}$ and $\mathcal{T}_{2}$. We considered two data generating processes. The first one is the logistic STR model with two regimes. That is, data were generated by 


$$
\begin{aligned}
y_{t} & =\mu+\nu_{1} g_{1}\left(\mathbf{z}_{1 t}\right)+\alpha x_{t}+\beta_{1} x_{t} g_{1}\left(\mathbf{z}_{1 t}\right)+u_{t} \\
g_{1}\left(\mathbf{z}_{1 t}\right) & =\frac{1}{1+e^{-\gamma_{11}\left(x_{t}-c_{11}\right)}}-\frac{1}{2} \\
\left(\begin{array}{l}
u_{t} \\
\Delta x_{t}
\end{array}\right) & =\varepsilon_{t}+B \varepsilon_{t-1} ; B=\left[\begin{array}{cc}
\omega & \omega \\
0 & \omega
\end{array}\right] \\
\varepsilon_{t} & \sim i i d N\left(0,\left[\begin{array}{ll}
1 & 0.5 \\
0.5 & 1
\end{array}\right]\right)
\end{aligned}
$$

In this data generation, the coefficient for $x_{t}$ moves slowly between $\alpha-\frac{1}{2} \beta_{1}$ and $\alpha+\frac{1}{2} \beta_{1}$ and the intercept term shows similar movements. In addition, the regressor $x_{t}$ and the error term $u_{t}$ are serially and contemporaneously correlated. The degree of correlation is controlled by the parameter $\omega$. Larger values of $\omega$ imply that the regressors and errors are more correlated both serially and contemporaneously. Also, $\left\{x_{t}\right\}$ were generated such that $c_{11}$ is located between the 15 th and 85 th percentiles of $\left\{x_{t}\right\}$. The purpose of this scheme is to make the data generating process nonlinear under the alternative of nonlinearity without any exception. The parameter values for the experiment using (16) are: $\left(\nu_{1}, \beta_{1}\right)=(0,0),(0,0.5),(0.5,0),(0.5,0.5), \mu=$ $\alpha=c_{11}=0$ and $\gamma_{11}=1,5, \infty^{6}$. The parameter values $\left(\nu_{1}, \beta_{1}\right)=(0,0)$ correspond to the null of linearity, and the rest to the alternative of nonlinearity. We tried two sample sizes $T=100$ and $T=200$; and the numbers of leads and lags $(K)$ used were 1, 2 and 3. Nominal size was set at $5 \%$ and 5,000 iterations were performed to calculate the empirical size and power of test statistics $\mathcal{T}_{1}$ and $\mathcal{T}_{2}$. The results are reported in Table 1.

The second data generation we considered is the three-regime, logistic smooth transition model

$$
\begin{aligned}
y_{t} & =\mu+\sum_{j=1}^{2} \nu_{j} g_{j}\left(\mathbf{z}_{j t}\right)+\alpha x_{t}+\sum_{j=1}^{2} \beta_{j} x_{t} g_{j}\left(\mathbf{z}_{j t}\right)+u_{t} \\
g\left(\mathbf{z}_{1 t}\right) & =\frac{1}{1+e^{-\gamma_{11}\left(x_{t}-c_{11}\right)}}-\frac{1}{2} ; g\left(\mathbf{z}_{2 t}\right)=\frac{1}{1+e^{-\gamma_{21}\left(x_{t}-c_{21}\right)}}-\frac{1}{2} \\
\left(\begin{array}{l}
u_{t} \\
\Delta x_{t}
\end{array}\right) & =\varepsilon_{t}+B \varepsilon_{t-1} ; B=\left[\begin{array}{ll}
\omega & \omega \\
0 & \omega
\end{array}\right] ; \\
\varepsilon_{t} & \sim \operatorname{iidN}\left(0,\left[\begin{array}{ll}
1 & 0.5 \\
0.5 & 1
\end{array}\right]\right) .
\end{aligned}
$$

When $c_{21}>c_{11}$, the coefficient for $x_{t}$ changes slowly from $\alpha-\frac{1}{2} \beta_{1}-\frac{1}{2} \beta_{2}$ via $\alpha+\frac{1}{2} \beta_{1}-$ $\frac{1}{2} \beta_{2}$ to $\alpha+\frac{1}{2} \beta_{1}+\frac{1}{2} \beta_{2}$ for increasing values of $x_{t}$. The coefficient for the intercept term changes similarly. As for the data generating process (16), the regressor and error are serially and contemporaneously correlated in (17). Also, $\left\{x_{t}\right\}$ were generated such

\footnotetext{
${ }^{6}$ When $\gamma_{11}=\infty$, the transition function was generated by $g_{1}\left(\mathbf{z}_{1 t}\right)=1\left\{x_{t}>c_{11}\right\}-\frac{1}{2}$ where $1\{\cdot\}$ is an indicator function.
} 
that $c_{11}$ is greater than the 15 th percentile of $\left\{x_{t}\right\}$ and $c_{12}$ less than 85 th percentiles of $\left\{x_{t}\right\}$. Thus, the data generating process (17) is always nonlinear under the alternative of nonlinearity. We set $\mu=\alpha=c_{11}=0, c_{21}=10$, and considered $\left(\nu_{1}, \nu_{2}, \beta_{1}, \beta_{2}\right)=$ $(0.0,0.0,0.0,0.0),(0.0,0.0,0.5,0.5),(0.5,0.5,0.0,0.0),(0.5,0.5,0.5,0.5)$ and $\left(\gamma_{11}, \gamma_{21}\right)=$ $(1,1),(5,5),(\infty, \infty)^{7}$. The null hypothesis of linearity corresponds to $\left(\nu_{1}, \nu_{2}, \beta_{1}, \beta_{2}\right)=$ $(0.0,0.0,0.0,0.0)$. The employed sample sizes, numbers of leads and lags, nominal size and number of iterations are the same as for Table 1 . The results for the data generating process (17) are reported in Table 2.

We may summarize the simulation results in Tables 1 and 2 as follows.

- Both tests keep the nominal size reasonably well in all the cases we considered, though slight over-rejections are observed. Comparing the two test statistics, $\mathcal{T}_{2}$ tends to reject more frequently than $\mathcal{T}_{1}$ under the null hypothesis. Moreover, the rejection frequencies of both tests tend to increase under the null hypothesis when the serial and contemporaneous correlations increase. As the sample size grows, the empirical size of the tests improves.

- The power of both tests improves as the sample size becomes larger.

- Test statistic $\mathcal{T}_{2}$ tends to reject more often than $\mathcal{T}_{1}$. However, considering the tendency of test statistic $\mathcal{T}_{2}$ to reject more often under the null hypothesis, neither one of the tests seems to dominate the other.

- When only the intercept term is subject to nonlinearity (i.e., in the cases $\left(\nu_{1}, \beta_{1}\right)=(0.5,0.0)$ and $\left.\left(\nu_{1}, \nu_{2}, \beta_{1}, \beta_{2}\right)=(0.5,0.5,0.0,0.0)\right)$, test statistic $\mathcal{T}_{2}$ tends to be slightly more powerful than $\mathcal{T}_{1}$ in Table 2 , but not particularly so in Table 1.

- The power of the tests does not seem to be sensitive to the values of the parameters $\gamma_{11}$ and $\gamma_{21}$. But in Table 1 , the power of test statistics $\mathcal{T}_{1}$ and $\mathcal{T}_{2}$ tends to be lower at $\gamma_{11}=\infty$ than at $\gamma_{11}=1,5$.

- The empirical size and power of the tests are not affected significantly by the choice of the value of $K$.

\section{Applications to the U.S. Money Demand Function}

Estimation of a money demand function has been an important research topic in macroeconomics since the late 1950s. More recently, methods for nonstationary time series have been applied to the money demand function and stable cointegrating relations of the relevant variables have been statistically confirmed (cf. Baba et al. (1992), Hendry and Ericsson (1991), Hoffman and Rasche (1991), Hoffman, Rasche and Tieslau (1995), Lütkepohl, Teräsvirta and Wolters (1999) and Stock and Watson (1993)). All of these studies using cointegration tests and estimation methods are based on linear model specifications except Lütkepohl et al. (1999), which employs the STR model for the differences of the German M1. However, economic theories for money demand (e.g., Baba et al. (1992), Baumol (1952) and Tobin (1956)) do not require the money demand function be linear. In empirical analyses, linear specifications are only used for econometric tractability and possibilities of nonlinear specifications in levels need to be explored further. As a first step in this direction,

\footnotetext{
${ }^{7}$ We used indicator functions to generate the transition functions in the case $\left(\gamma_{11}, \gamma_{21}\right)=(\infty, \infty)$.
} 
this section tests the null of linearity for the U.S. money demand function using the tests developed in Section 3.

In this paper, we focus on the U.S. quarterly data that starts in 1959:Q1. The data we use are M1 for money, GDP for income, GDP deflator for price level and the 90-day Treasury bill rate for a short-term interest rate. These data were taken from International Financial Statistics. Note that the M1 and GDP series are seasonally adjusted. Three variables - real M1, real GDP and the Treasury bill rate-were used for our linearity tests. Natural logs were taken of the real M1 and real GDP. Natural $\log$ is not taken of the Treasury bill rate when structural regressions are fit in most previous studies (e.g., Stock and Watson (1993)). But cointegration tests are applied to the natural log of the Treasury bill rate in some other studies (e.g., Hoffman and Rasche (1991)). Thus, we consider both types of the Treasury bill rates in this study.

In Table 3, we report the test results for the sampling periods 1959:Q1-1985:Q4, 1959:Q1-1990:Q4, 1959:Q1-1995:Q4 and 1959:Q1-2000:Q4. Transition variables in Table 3 imply the variables appearing in the transition function $g_{j}(\cdot)$. To calculate the tests, the real M1 was regressed on the real GDP, Treasury bill rate, leads and lags of these variables, and the products of the real GDP and Treasury bill rate. For example, regressors used for the $\mathcal{T}_{1}$ test in the first row of part (1) of Table 3 are the real GDP, Treasury bill rate, leads and lags of these variables and the squares of the Treasury bill rate; and those for the second row are the real GDP, Treasury bill rate, leads and lags of these variables, the squares of the Treasury bill rate and the product of the real GDP and Treasury bill rate. Various sampling periods were examined to study the effects of sampling periods on the test results. Part (1) of Table 3 shows that evidence for nonlinearity is found for the sampling period 1959:Q1-2000:Q4, but none for the rest. The evidence is stronger when the real GDP is the transition variable. This implies that the money demand may have a nonlinear relationship with the real GDP and Treasury bill rate that depends on the level of real GDP. Using the Treasury bill rate without taking the natural log as in part (2) does not bring any noticeable changes to the test results.

In the U.S. economy, M1 contracted substantially during the period 1974-1976. This episode of missing-money led some researchers to doubt the stability of the money demand equation (cf. Goldfeld (1976)) and generated research interest in finding constant-parameter models for M1 (cf. Hendry and Ericsson (1991)). Because the missing-money period may have affected our test results, we performed linearity tests excluding the sampling period 1974-1976. The results, reported in Table 4, indicate some evidence for nonlinearity for both the sampling periods. As in Table 3, the evidence becomes stronger during the period 1977-2000 when the real GDP is the transition variable. During the period 1959-1973, we observe evidence of nonlinearity when the Treasury bill rate is used as the transition variable. When we do not take the natural log of the Treasury bill rate, we observe stronger evidence for nonlinearity.

Tables 3 and 4 indicate that the results of the linearity tests are sensitive to sampling periods and that strong evidence of nonlinearity is obtained when the data from late 1990s are included in the sample. Why the data from late 1990s induce nonlinearity is a question that awaits further study. Moreover, fitting appropriate 
smooth transition regression models for the variables we have studied needs further investigation.

\section{Conclusion}

We have developed tests that can be used to test linearity in a general cointegrating STR model with $I(1)$ regressors. The regressors and errors of the model are allowed to be serially and contemporaneously correlated. In order to allow for this feature, an endogeneity correction based on a leads-and-lags approach is employed. The model's transition mechanism is assumed to be more general than previously. The application of the proposed tests is simple because OLS techniques and standard chisquare limiting distributions apply. Simulation experiments indicate that the tests have reasonable finite sample properties. In empirical applications some evidence of nonlinearity in the U.S. money demand function is found particularly when the data from late 1990s are included in the sample. 
TABLE 1

Empirical Size and Power of Nonlinearity Tests: the Case of Two REGIMES

Notes:(i) Data generating process:

$$
\begin{aligned}
y_{t} & =\mu+\nu_{1} g_{1}\left(\mathbf{z}_{1 t}\right)+\alpha x_{t}+\beta_{1} x_{t} g_{1}\left(\mathbf{z}_{1 t}\right)+u_{t} \\
g_{1}\left(\mathbf{z}_{1 t}\right) & =\frac{1}{1+e^{-\gamma_{11}\left(x_{t}-c_{11}\right)}}-\frac{1}{2} ; \mu=\alpha=c_{11}=0 \\
\left(\begin{array}{l}
u_{t} \\
\Delta x_{t}
\end{array}\right) & =\varepsilon_{t}+B \varepsilon_{t-1} ; B=\left[\begin{array}{ll}
\omega & \omega \\
0 & \omega
\end{array}\right] \\
\varepsilon_{t} & \sim \operatorname{iidN}\left(0,\left[\begin{array}{ll}
1 & 0.5 \\
0.5 & 1
\end{array}\right]\right) .
\end{aligned}
$$

(ii) The parameter values $\left(\nu_{1}, \beta_{1}\right)=(0,0)$ correspond to the null of linearity, and the rest to the alternative of nonlinearity.

(iii) Larger $\gamma_{11}$ implies more abrupt change of regimes.

(iv) Larger $\omega$ implies that the regressors and errors are more correlated both serially and contemporaneously.

(v) The number of iterations is 5,000, and the nominal size $5 \%$.

(vi) The long-run variance was estimated using Andrews' (1991) methods with an AR(4) approximation for the prefilter.

$$
\text { (1) } \gamma_{11}=1
$$

\begin{tabular}{ccccccccc}
\hline & & & \multicolumn{3}{c}{$\mathcal{T}_{1}$} & \multicolumn{3}{c}{$\mathcal{T}_{2}$} \\
\hline Correlation & Sample size & $\left(\nu_{1}, \beta_{1}\right)$ & $K=1$ & $K=2$ & $K=3$ & $K=1$ & $K=2$ & $K=3$ \\
\hline \hline \multirow{5}{*}{$T=100$} & $(0.0,0.0)$ & 0.064 & 0.071 & 0.076 & 0.072 & 0.076 & 0.083 \\
& & $(0.0,0.5)$ & 0.853 & 0.844 & 0.835 & 0.867 & 0.855 & 0.852 \\
& & $(0.5,0.0)$ & 0.120 & 0.125 & 0.128 & 0.118 & 0.122 & 0.131 \\
& & $(0.5,0.5)$ & 0.836 & 0.830 & 0.824 & 0.859 & 0.854 & 0.842 \\
\cline { 3 - 9 } & \multirow{3}{*}{$T=200$} & $(0.0,0.0)$ & 0.057 & 0.061 & 0.062 & 0.058 & 0.060 & 0.064 \\
& & $(0.0,0.5)$ & 0.968 & 0.967 & 0.967 & 0.988 & 0.985 & 0.984 \\
& & $(0.5,0.0)$ & 0.176 & 0.176 & 0.176 & 0.167 & 0.176 & 0.174 \\
& & $(0.5,0.5)$ & 0.957 & 0.955 & 0.955 & 0.977 & 0.976 & 0.976 \\
\hline \multirow{5}{*}{$T=100$} & $(0.0,0.0)$ & 0.070 & 0.078 & 0.082 & 0.074 & 0.080 & 0.085 \\
& & $(0.0,0.5)$ & 0.889 & 0.888 & 0.886 & 0.916 & 0.912 & 0.910 \\
& & $(0.5,0.0)$ & 0.116 & 0.119 & 0.122 & 0.107 & 0.122 & 0.124 \\
& & $(0.5,0.5)$ & 0.880 & 0.876 & 0.874 & 0.904 & 0.906 & 0.898 \\
\hline \multirow{3}{*}{$T=200$} & $(0.0,0.0)$ & 0.060 & 0.062 & 0.066 & 0.062 & 0.062 & 0.064 \\
& & $(0.0,0.5)$ & 0.984 & 0.983 & 0.983 & 0.995 & 0.995 & 0.995 \\
& & $(0.5,0.0)$ & 0.162 & 0.163 & 0.166 & 0.154 & 0.166 & 0.159 \\
& & $(0.5,0.5)$ & 0.972 & 0.972 & 0.973 & 0.986 & 0.987 & 0.987 \\
\hline
\end{tabular}


(2) $\gamma_{11}=5$

\begin{tabular}{ccccccccc}
\hline & & & \multicolumn{3}{c}{$\mathcal{T}_{1}$} & \multicolumn{3}{c}{$\mathcal{T}_{2}$} \\
\hline Correlation & Sample size & $\left(\nu_{1}, \beta_{1}\right)$ & $K=1$ & $K=2$ & $K=3$ & $K=1$ & $K=2$ & $K=3$ \\
\hline \hline \multirow{5}{*}{$T=100$} & $(0.0,0.0)$ & 0.071 & 0.077 & 0.079 & 0.072 & 0.075 & 0.086 \\
& & $(0.0,0.5)$ & 0.849 & 0.839 & 0.836 & 0.846 & 0.839 & 0.832 \\
& & $(0.5,0.0)$ & 0.145 & 0.149 & 0.152 & 0.139 & 0.150 & 0.158 \\
& & $(0.5,0.5)$ & 0.822 & 0.821 & 0.817 & 0.845 & 0.840 & 0.832 \\
\cline { 3 - 9 } & \multirow{3}{*}{$T=200$} & $(0.0,0.0)$ & 0.058 & 0.060 & 0.062 & 0.060 & 0.062 & 0.066 \\
& & $(0.0,0.5)$ & 0.978 & 0.977 & 0.976 & 0.991 & 0.990 & 0.989 \\
& $(0.5,0.0)$ & 0.202 & 0.200 & 0.202 & 0.201 & 0.205 & 0.201 \\
& & $(0.5,0.5)$ & 0.957 & 0.955 & 0.954 & 0.974 & 0.974 & 0.973 \\
\hline \multirow{5}{*}{$T=100$} & $(0.0,0.0)$ & 0.070 & 0.078 & 0.078 & 0.074 & 0.076 & 0.084 \\
& & $(0.0,0.5)$ & 0.893 & 0.889 & 0.887 & 0.907 & 0.904 & 0.901 \\
& & $(0.5,0.0)$ & 0.126 & 0.133 & 0.134 & 0.125 & 0.134 & 0.139 \\
& \multirow{3}{*}{$T=200$} & $(0.5,0.5)$ & 0.880 & 0.873 & 0.868 & 0.891 & 0.891 & 0.882 \\
\hline & & $(0.0,0.0)$ & 0.067 & 0.066 & 0.073 & 0.063 & 0.064 & 0.069 \\
& & $(0.0,0.5)$ & 0.986 & 0.985 & 0.987 & 0.995 & 0.994 & 0.993 \\
& $(0.5,0.0)$ & 0.174 & 0.171 & 0.170 & 0.161 & 0.171 & 0.169 \\
& & $(0.5,0.5)$ & 0.973 & 0.973 & 0.974 & 0.986 & 0.987 & 0.986 \\
\hline
\end{tabular}

(3) $\gamma_{11}=\infty$

\begin{tabular}{|c|c|c|c|c|c|c|c|c|}
\hline & & & \multicolumn{3}{|c|}{$\mathcal{T}_{1}$} & \multicolumn{3}{|c|}{$\mathcal{T}_{2}$} \\
\hline Correlation & Sample size & $\left(\nu_{1}, \beta_{1}\right)$ & $K=1$ & $K=2$ & $K=3$ & $K=1$ & $K=2$ & $K=3$ \\
\hline \multirow{8}{*}{$\omega=0.2$} & \multirow{4}{*}{$T=100$} & $(0.0,0.0)$ & $\overline{0.062}$ & 0.068 & 0.072 & $\overline{0.074}$ & $\overline{0.077}$ & 0.085 \\
\hline & & $(0.0,0.5)$ & 0.781 & 0.771 & 0.764 & 0.762 & 0.753 & 0.743 \\
\hline & & $(0.5,0.0)$ & 0.120 & 0.120 & 0.121 & 0.120 & 0.126 & 0.130 \\
\hline & & $(0.5,0.5)$ & 0.755 & 0.753 & 0.736 & 0.756 & 0.749 & 0.738 \\
\hline & \multirow{4}{*}{$T=200$} & $(0.0,0.0)$ & 0.057 & 0.062 & 0.064 & 0.061 & 0.065 & 0.067 \\
\hline & & $(0.0,0.5)$ & 0.966 & 0.965 & 0.964 & 0.978 & 0.977 & 0.975 \\
\hline & & $(0.5,0.0)$ & 0.160 & 0.162 & 0.167 & 0.156 & 0.159 & 0.163 \\
\hline & & $(0.5,0.5)$ & 0.940 & 0.941 & 0.938 & 0.962 & 0.964 & 0.959 \\
\hline \multirow{8}{*}{$\omega=0.5$} & \multirow{4}{*}{$T=100$} & $(0.0,0.0)$ & 0.079 & 0.081 & 0.085 & 0.077 & 0.085 & 0.092 \\
\hline & & $(0.0,0.5)$ & 0.818 & 0.811 & 0.803 & 0.811 & 0.809 & 0.800 \\
\hline & & $(0.5,0.0)$ & 0.104 & 0.111 & 0.115 & 0.103 & 0.121 & 0.126 \\
\hline & & $(0.5,0.5)$ & 0.804 & 0.804 & 0.798 & 0.808 & 0.804 & 0.794 \\
\hline & \multirow{4}{*}{$T=200$} & $(0.0,0.0)$ & 0.058 & 0.060 & 0.061 & 0.063 & 0.064 & 0.069 \\
\hline & & $(0.0,0.5)$ & 0.972 & 0.973 & 0.972 & 0.987 & 0.986 & 0.984 \\
\hline & & $(0.5,0.0)$ & 0.148 & 0.150 & 0.152 & 0.137 & 0.144 & 0.145 \\
\hline & & $(0.5,0.5)$ & 0.960 & 0.961 & 0.960 & 0.976 & 0.977 & 0.976 \\
\hline
\end{tabular}


TABLE 2

Empirical Size and Power of Nonlinearity Tests: the Case of Three REGIMES

Notes:(i) Data generating process:

$$
\begin{aligned}
y_{t} & =\mu+\sum_{j=1}^{2} \nu_{j} g_{j}\left(\mathbf{z}_{j t}\right)+\alpha x_{t}+\sum_{j=1}^{2} \beta_{j} g_{j}\left(\mathbf{z}_{j t}\right)+u_{t} \\
g_{j}\left(\mathbf{z}_{j t}\right) & =\frac{1}{1+e^{-\gamma_{j 1}\left(x_{t}-c_{j 1}\right)}}-\frac{1}{2} ; \mu=\alpha=c_{11}=0, c_{21}=10 \\
\left(\begin{array}{l}
u_{t} \\
\Delta x_{t}
\end{array}\right) & =\varepsilon_{t}+B \varepsilon_{t-1} ; B=\left[\begin{array}{cc}
\omega & \omega \\
0 & \omega
\end{array}\right] \\
\varepsilon_{t} & \sim i i d N\left(0,\left[\begin{array}{ll}
1 & 0.5 \\
0.5 & 1
\end{array}\right]\right)
\end{aligned}
$$

(ii) The parameter values $\left(\nu_{1}, \nu_{2}, \beta_{1}, \beta_{2}\right)=(0,0,0,0)$ correspond to the null of linearity, and the rest to the alternative of nonlinearity.

(iii) Larger $\gamma_{11}$ and $\gamma_{21}$ imply more abrupt change of regimes.

(iv) Larger $\omega$ implies that the regressors and errors are more correlated both serially and contemporaneously.

(v) The number of iterations is 5,000, and the nominal size $5 \%$.

(vi) The long-run variance was estimated using Andrews' (1991) methods with an AR(4) approximation for the prefilter.

(1) $\gamma_{11}=\gamma_{21}=1$

\begin{tabular}{ccccccccc}
\hline & & & & $\mathcal{T}_{1}$ & \multicolumn{4}{c}{$\mathcal{T}_{2}$} \\
\hline Correlation & Sample size & $\left(\nu_{1}, \nu_{2}, \beta_{1}, \beta_{2}\right)$ & $K=1$ & $K=2$ & $K=3$ & $K=1$ & $K=2$ & $K=3$ \\
\hline \hline \multirow{5}{*}{$T=100$} & $(0.0,0.0,0.0,0.0)$ & 0.062 & 0.066 & 0.071 & 0.067 & 0.071 & 0.081 \\
& & $(0.0,0.0,0.5,0.5)$ & 0.982 & 0.984 & 0.984 & 0.971 & 0.967 & 0.972 \\
& & $(0.5,0.5,0.0,0.0)$ & 0.144 & 0.151 & 0.156 & 0.144 & 0.157 & 0.159 \\
& & $(0.5,0.5,0.5,0.5)$ & 0.975 & 0.977 & 0.978 & 0.963 & 0.964 & 0.968 \\
\cline { 3 - 9 } & \multirow{3}{*}{$T=200$} & $(0.0,0.0,0.0,0.0)$ & 0.063 & 0.066 & 0.067 & 0.062 & 0.060 & 0.062 \\
& & $(0.0,0.0,0.5,0.5)$ & 0.985 & 0.985 & 0.986 & 0.982 & 0.982 & 0.982 \\
& $(0.5,0.5,0.0,0.0)$ & 0.306 & 0.303 & 0.305 & 0.380 & 0.390 & 0.379 \\
& & $(0.5,0.5,0.5,0.5)$ & 0.978 & 0.977 & 0.978 & 0.983 & 0.984 & 0.984 \\
\hline \multirow{4}{*}{$T=100$} & $(0.0,0.0,0.0,0.0)$ & 0.074 & 0.078 & 0.087 & 0.075 & 0.083 & 0.092 \\
& & $(0.0,0.0,0.5,0.5)$ & 0.983 & 0.982 & 0.982 & 0.982 & 0.978 & 0.979 \\
& & $(0.5,0.5,0.0,0.0)$ & 0.178 & 0.178 & 0.178 & 0.170 & 0.201 & 0.191 \\
& & $(0.5,0.5,0.5,0.5)$ & 0.967 & 0.966 & 0.966 & 0.984 & 0.979 & 0.980 \\
\hline \multirow{3}{*}{$T=200$} & $(0.0,0.0,0.0,0.0)$ & 0.059 & 0.062 & 0.065 & 0.059 & 0.058 & 0.058 \\
& $(0.0,0.0,0.5,0.5)$ & 0.993 & 0.993 & 0.992 & 0.996 & 0.995 & 0.995 \\
& & $(0.5,0.5,0.0,0.0)$ & 0.327 & 0.325 & 0.322 & 0.395 & 0.448 & 0.417 \\
& & $(0.5,0.5,0.5,0.5)$ & 0.983 & 0.982 & 0.983 & 0.995 & 0.996 & 0.995 \\
\hline
\end{tabular}


(2) $\gamma_{11}=\gamma_{21}=5$

\begin{tabular}{|c|c|c|c|c|c|c|c|c|}
\hline & & & & $\mathcal{T}_{1}$ & & & $\mathcal{T}_{2}$ & \\
\hline Correlation & Sample size & $\left(\nu_{1}, \nu_{2}, \beta_{1}, \beta_{2}\right)$ & $K=1$ & $K=2$ & $K=3$ & $K=1$ & $K=2$ & $K=3$ \\
\hline \multirow{8}{*}{$\omega=0.2$} & \multirow{4}{*}{$T=100$} & 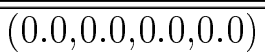 & "0.067 & "0.072 & "0.078 & "0.068 & "0.072 & "0.078 \\
\hline & & $(0.0,0.0,0.5,0.5)$ & 0.973 & 0.973 & 0.975 & 0.935 & 0.937 & 0.941 \\
\hline & & $(0.5,0.5,0.0,0.0)$ & 0.163 & 0.160 & 0.166 & 0.161 & 0.168 & 0.174 \\
\hline & & $(0.5,0.5,0.5,0.5)$ & 0.955 & 0.958 & 0.958 & 0.927 & 0.928 & 0.935 \\
\hline & \multirow{4}{*}{$T=200$} & $(0.0,0.0,0.0,0.0)$ & 0.058 & 0.061 & 0.064 & 0.056 & 0.054 & 0.059 \\
\hline & & $(0.0,0.0,0.5,0.5)$ & 0.984 & 0.985 & 0.985 & 0.979 & 0.979 & 0.978 \\
\hline & & $(0.5,0.5,0.0,0.0)$ & 0.311 & 0.307 & 0.305 & 0.375 & 0.385 & 0.377 \\
\hline & & $(0.5,0.5,0.5,0.5)$ & 0.968 & 0.969 & 0.970 & 0.972 & 0.973 & 0.972 \\
\hline \multirow{8}{*}{$\omega=0.5$} & \multirow{4}{*}{$T=100$} & $(0.0,0.0,0.0,0.0)$ & 0.073 & 0.076 & 0.085 & 0.068 & 0.075 & 0.086 \\
\hline & & $(0.0,0.0,0.5,0.5)$ & 0.978 & 0.977 & 0.977 & 0.971 & 0.968 & 0.968 \\
\hline & & $(0.5,0.5,0.0,0.0)$ & 0.180 & 0.182 & 0.178 & 0.169 & 0.204 & 0.194 \\
\hline & & $(0.5,0.5,0.5,0.5)$ & 0.964 & 0.963 & 0.963 & 0.970 & 0.968 & 0.968 \\
\hline & \multirow{4}{*}{$T=200$} & $(0.0,0.0,0.0,0.0)$ & 0.061 & 0.065 & 0.064 & 0.063 & 0.065 & 0.069 \\
\hline & & $(0.0,0.0,0.5,0.5)$ & 0.989 & 0.989 & 0.989 & 0.991 & 0.991 & 0.989 \\
\hline & & $(0.5,0.5,0.0,0.0)$ & 0.337 & 0.335 & 0.332 & 0.413 & 0.464 & 0.428 \\
\hline & & $(0.5,0.5,0.5,0.5)$ & 0.979 & 0.980 & 0.980 & 0.990 & 0.989 & 0.989 \\
\hline
\end{tabular}

(3) $\gamma_{11}=\gamma_{21}=\infty$

\begin{tabular}{|c|c|c|c|c|c|c|c|c|}
\hline & & & & $\overline{\mathcal{T}_{1}}$ & & & $\overline{\mathcal{T}_{2}}$ & \\
\hline Correlation & Sample size & $\left(\nu_{1}, \nu_{2}, \beta_{1}, \beta_{2}\right)$ & $K=1$ & $K=2$ & $K=3$ & $K=1$ & $K=2$ & $K=3$ \\
\hline \multirow{8}{*}{$\omega=0.2$} & \multirow{4}{*}{$T=100$} & $(0.0,0.0,0.0,0.0)$ & 0.067 & 0.072 & 0.076 & 0.067 & 0.075 & 0.085 \\
\hline & & $(0.0,0.0,0.5,0.5)$ & 0.969 & 0.972 & 0.971 & 0.928 & 0.932 & 0.934 \\
\hline & & $(0.5,0.5,0.0,0.0)$ & 0.163 & 0.163 & 0.170 & 0.151 & 0.158 & 0.161 \\
\hline & & $(0.5,0.5,0.5,0.5)$ & 0.958 & 0.958 & 0.957 & 0.908 & 0.915 & 0.920 \\
\hline & \multirow{4}{*}{$T=200$} & $(0.0,0.0,0.0,0.0)$ & 0.067 & 0.065 & 0.066 & 0.062 & 0.064 & 0.066 \\
\hline & & $(0.0,0.0,0.5,0.5)$ & 0.985 & 0.985 & 0.985 & 0.976 & 0.977 & 0.976 \\
\hline & & $(0.5,0.5,0.0,0.0)$ & 0.308 & 0.307 & 0.307 & 0.388 & 0.401 & 0.396 \\
\hline & & $(0.5,0.5,0.5,0.5)$ & 0.969 & 0.970 & 0.970 & 0.974 & 0.972 & 0.971 \\
\hline \multirow{8}{*}{$\omega=0.5$} & \multirow{4}{*}{$T=100$} & $(0.0,0.0,0.0,0.0)$ & 0.067 & 0.072 & 0.075 & 0.076 & 0.080 & 0.086 \\
\hline & & $(0.0,0.0,0.5,0.5)$ & 0.973 & 0.973 & 0.975 & 0.964 & 0.961 & 0.962 \\
\hline & & $(0.5,0.5,0.0,0.0)$ & 0.176 & 0.182 & 0.188 & 0.171 & 0.211 & 0.206 \\
\hline & & $(0.5,0.5,0.5,0.5)$ & 0.961 & 0.961 & 0.962 & 0.959 & 0.962 & 0.959 \\
\hline & \multirow{4}{*}{$T=200$} & $(0.0,0.0,0.0,0.0)$ & 0.060 & 0.063 & 0.064 & 0.061 & 0.061 & 0.063 \\
\hline & & $(0.0,0.0,0.5,0.5)$ & 0.989 & 0.989 & 0.989 & 0.990 & 0.990 & 0.990 \\
\hline & & $(0.5,0.5,0.0,0.0)$ & 0.320 & 0.318 & 0.321 & 0.399 & 0.451 & 0.422 \\
\hline & & $(0.5,0.5,0.5,0.5)$ & 0.982 & 0.982 & 0.983 & 0.990 & 0.989 & 0.988 \\
\hline
\end{tabular}


TABLE 3

Linearity Test Results for the U.S. Money Demand Function

Notes: (i) RTB denotes either the natural log of the 90-day Treasury bill rate or the Treasury bill rate, and RGDP the natural log of real GDP.

(ii) The long-run variance was estimated using Andrews' (1991) methods with an AR(4) approximation for the prefilter.

(iii) $\left(^{*}\right)$ : significant at the $5 \%$ level; $\left({ }^{* *}\right)$ : significant at the $1 \%$ level.

(iv) To calculate the tests, the real M1 was regressed on the real GDP, Treasury bill rate, leads and lags of these variables, and the products of the real GDP and Treasury bill rate. Transition variables imply the variables appearing in the transition function $g_{j}(\cdot)$.

(1) Log taken of the Treasury bill rate

\begin{tabular}{|c|c|c|c|c|c|c|c|c|}
\hline \multirow{2}{*}{$\begin{array}{c}\text { Sampling } \\
\text { period }\end{array}$} & \multirow{2}{*}{$\begin{array}{c}\text { Transtion } \\
\text { variable }\end{array}$} & \multirow{2}{*}{$\begin{array}{c}\text { Regressors } \\
\text { s.t. transition }\end{array}$} & \multicolumn{3}{|c|}{$\mathcal{T}_{1}$} & \multicolumn{3}{|c|}{$\mathcal{T}_{2}$} \\
\hline & & & $K=1$ & $K=2$ & $K=3$ & $K=1$ & $K=2$ & $K=3$ \\
\hline \multirow{5}{*}{$\begin{array}{l}1959-1985 \\
(T=108)\end{array}$} & "RTB & " RTB & 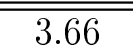 & 3.23 & 3.48 & 3.68 & 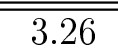 & ב3.53 \\
\hline & & RTB, RGDP & 3.95 & 3.42 & 3.64 & 4.13 & 3.63 & 3.88 \\
\hline & RGDP & RTB, RGDP & 4.01 & 3.41 & 3.63 & 5.42 & 4.41 & 4.40 \\
\hline & & RGDP & 2.14 & 2.32 & 2.96 & 4.94 & 4.10 & 4.17 \\
\hline & RTB, RGDP & RTB, RGDP & 4.01 & 3.42 & 3.64 & 5.89 & 4.90 & 4.96 \\
\hline \multirow{5}{*}{$\begin{array}{l}1959-1990 \\
(T=128)\end{array}$} & RTB & RTB & 2.66 & 2.78 & 3.05 & 2.71 & 2.82 & 3.09 \\
\hline & & RTB, RGDP & 2.73 & 2.84 & 3.10 & 2.75 & 2.85 & 3.11 \\
\hline & RGDP & RTB, RGDP & 4.71 & 4.46 & 4.94 & 5.17 & 4.85 & 5.21 \\
\hline & & RGDP & 0.00 & 0.06 & 0.18 & 3.01 & 2.97 & 3.32 \\
\hline & RTB, RGDP & RTB, RGDP & 4.84 & 4.45 & 4.97 & 5.75 & 5.37 & 5.66 \\
\hline \multirow{5}{*}{$\begin{array}{l}1959-1995 \\
(T=148)\end{array}$} & RTB & RTB & 2.69 & 2.94 & 2.72 & 2.90 & 3.08 & 2.84 \\
\hline & & RTB, RGDP & 3.28 & 3.55 & 3.32 & 3.31 & 3.55 & 3.32 \\
\hline & RGDP & RTB, RGDP & 2.88 & 2.52 & 2.24 & 3.51 & 3.09 & 2.66 \\
\hline & & RGDP & 0.07 & 0.01 & 0.10 & 2.75 & 2.49 & 2.22 \\
\hline & RTB, RGDP & RTB, RGDP & 4.93 & 4.81 & 4.48 & 6.51 & 6.27 & 5.85 \\
\hline \multirow{5}{*}{$\begin{array}{l}1959-2000 \\
(T=168)\end{array}$} & RTB & RTB & $19.72^{* *}$ & 3.35 & 2.63 & $20.1^{* *}$ & 3.37 & 2.63 \\
\hline & & RTB, RGDP & $34.18^{* *}$ & 4.57 & 3.19 & $35.1^{* *}$ & 4.69 & 3.26 \\
\hline & RGDP & RTB, RGDP & $69.6^{* *}$ & $9.07^{*}$ & $6.08^{*}$ & $86.8^{* *}$ & $10.5^{*}$ & 6.72 \\
\hline & & RGDP & $65.3^{* *}$ & $8.60^{* *}$ & $5.74^{*}$ & $70.4^{* *}$ & $8.82^{*}$ & 5.77 \\
\hline & RTB, RGDP & RTB, RGDP & $78.9^{* *}$ & $10.6^{*}$ & 6.94 & $125^{* *}$ & 15.5 & 10.1 \\
\hline
\end{tabular}


(2) No log taken of the Treasury bill rate

\begin{tabular}{|c|c|c|c|c|c|c|c|c|}
\hline \multirow{2}{*}{$\begin{array}{l}\text { Sampling } \\
\text { period }\end{array}$} & \multirow{2}{*}{$\begin{array}{c}\text { Transtion } \\
\text { variable }\end{array}$} & \multirow{2}{*}{$\begin{array}{c}\text { Regressors } \\
\text { s.t. transition }\end{array}$} & \multicolumn{3}{|c|}{$\mathcal{T}_{1}$} & \multicolumn{3}{|c|}{$\mathcal{T}_{2}$} \\
\hline & & & $K=1$ & $K=2$ & $K=3$ & $K=1$ & $K=2$ & $K=3$ \\
\hline \multirow{5}{*}{$\begin{array}{l}1959-1985 \\
(T=108)\end{array}$} & "RTB & RTB & 2.68 & 2.72 & 2.67 & 4.01 & 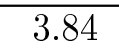 & 3.72 \\
\hline & & RTB, RGDP & 4.22 & 4.23 & 4.13 & 4.28 & 4.23 & 4.13 \\
\hline & RGDP & RTB, RGDP & 4.23 & 4.18 & 4.10 & 7.09 & 6.59 & 5.95 \\
\hline & & RGDP & 2.42 & 2.93 & 3.32 & 6.50 & 6.18 & 5.71 \\
\hline & RTB, RGDP & RTB, RGDP & 4.24 & 4.30 & 4.38 & 7.44 & 7.07 & 6.58 \\
\hline \multirow{5}{*}{$\begin{array}{l}1959-1990 \\
(T=128)\end{array}$} & RTB & RTB & 0.30 & 0.34 & 0.43 & 1.77 & 1.49 & 1.50 \\
\hline & & RTB, RGDP & 0.91 & 0.87 & 1.03 & 1.79 & 1.50 & 1.50 \\
\hline & RGDP & RTB, RGDP & 3.92 & 3.09 & 3.41 & 5.25 & 4.30 & 4.65 \\
\hline & & RGDP & 0.02 & 0.00 & 0.02 & 2.80 & 2.38 & 2.70 \\
\hline & RTB, RGDP & RTB, RGDP & 4.23 & 3.32 & 3.62 & 5.88 & 4.92 & 5.22 \\
\hline \multirow{5}{*}{$\begin{array}{l}1959-1995 \\
(T=148)\end{array}$} & RTB & RTB & 0.01 & 0.06 & 0.10 & 1.23 & 0.88 & 0.76 \\
\hline & & RTB, RGDP & 1.40 & 1.34 & 1.51 & 2.02 & 1.68 & 1.74 \\
\hline & RGDP & RTB, RGDP & 3.59 & 2.66 & 2.51 & $\overline{4.34}$ & 3.31 & 3.06 \\
\hline & & RGDP & 0.40 & 0.10 & 0.01 & 3.36 & 2.57 & 2.40 \\
\hline & RTB, RGDP & RTB, RGDP & 4.93 & 4.81 & 4.48 & 6.51 & 6.27 & 5.85 \\
\hline \multirow{5}{*}{$\begin{array}{l}1959-2000 \\
(T=168)\end{array}$} & RTB & RTB & 1.83 & 0.38 & 0.45 & 5.34 & 0.68 & 0.69 \\
\hline & & RTB, RGDP & $17.7^{* *}$ & 1.31 & 1.09 & $18.4^{* *}$ & 1.40 & 1.16 \\
\hline & RGDP & RTB, RGDP & $81.0^{* *}$ & $7.66^{*}$ & $6.64^{*}$ & $116^{* *}$ & $10.1^{*}$ & $8.55^{*}$ \\
\hline & & RGDP & $79.7^{* *}$ & $7.60^{* *}$ & $6.60^{*}$ & $99.2^{* *}$ & $8.86^{*}$ & $7.40^{*}$ \\
\hline & RTB, RGDP & RTB, RGDP & $83.4^{*}$ & $7.75^{*}$ & $6.71^{*}$ & $148^{* *}$ & 13.1 & 11.3 \\
\hline
\end{tabular}


TABLE 4

Linearity Test Results for the U.S. Money Demand Function EXCluding the PERIOd 1974-1976

Notes: (i) RTB denotes either the natural log of the 90-day Treasury bill rate or the Treasury bill rate, and RGDP the natural log of real GDP.

(ii) The long-run variance was estimated using Andrews' (1991) methods with an AR(4) approximation for the prefilter.

(iii) $\left({ }^{*}\right)$ : significant at the $5 \%$ level; $\left({ }^{* *}\right)$ : significant at the $1 \%$ level.

(iv) To calculate the tests, the real M1 was regressed on the real GDP, Treasury bill rate, leads and lags of these variables, and the products of the real GDP and Treasury bill rate. Transition variables imply the variables appearing in the transition function $g_{j}(\cdot)$.

(1) Log taken of the Treasury bill rate

\begin{tabular}{|c|c|c|c|c|c|c|c|c|}
\hline \multirow{2}{*}{$\begin{array}{l}\text { Sampling } \\
\text { period }\end{array}$} & \multirow{2}{*}{$\begin{array}{c}\text { Transtion } \\
\text { variable }\end{array}$} & \multirow{2}{*}{$\begin{array}{l}\text { Regressors } \\
\text { s.t. transition }\end{array}$} & \multicolumn{3}{|c|}{$\overline{\mathcal{T}_{1}}$} & \multicolumn{3}{|c|}{$\mathcal{T}_{2}$} \\
\hline & & & $K=1$ & $K=2$ & $K=3$ & $K=1$ & $K=2$ & $K=3$ \\
\hline \multirow{5}{*}{$\begin{array}{c}1959-1973 \\
(T=60)\end{array}$} & $\overline{\mathrm{RTB}}$ & $\overline{\mathrm{RTB}}$ & $4.58^{*}$ & $\overline{0.43}$ & $\overline{0.08}$ & $\overline{9.10}$ & $\overline{7.36}$ & 6.68 \\
\hline & & RTB, RGDP & 4.70 & 0.97 & 0.84 & 9.11 & 7.43 & 6.70 \\
\hline & RGDP & RTB, RGDP & 3.50 & 0.27 & 0.99 & 7.29 & 4.80 & 6.78 \\
\hline & & RGDP & 2.00 & 0.09 & 0.78 & 7.06 & 4.78 & 6.43 \\
\hline & RTB, RGDP & RTB, RGDP & 5.52 & 1.03 & 1.35 & 13.3 & 12.1 & 18.9 \\
\hline \multirow{5}{*}{$\begin{array}{c}1977-2000 \\
(T=96)\end{array}$} & RTB & RTB & 0.08 & 0.52 & 0.59 & 0.08 & 0.52 & 0.60 \\
\hline & & RTB, RGDP & 2.80 & 4.65 & $6.11^{*}$ & 2.88 & 4.80 & 6.45 \\
\hline & RGDP & RTB, RGDP & $8.59^{*}$ & $9.64^{* *}$ & $9.85^{* *}$ & $8.65^{*}$ & $9.65^{*}$ & $9.85^{*}$ \\
\hline & & RGDP & $8.58^{* *}$ & $9.64^{* *}$ & $9.85^{* *}$ & $8.64^{*}$ & $9.65^{* *}$ & $9.85^{* *}$ \\
\hline & RTB, RGDP & RTB, RGDP & $8.60^{*}$ & $9.64^{*}$ & $9.85^{*}$ & 9.01 & 10.1 & 10.3 \\
\hline
\end{tabular}

(2) No log taken of the Treasury bill rate

\begin{tabular}{|c|c|c|c|c|c|c|c|c|}
\hline \multirow{2}{*}{$\begin{array}{l}\text { Sampling } \\
\text { period }\end{array}$} & \multirow{2}{*}{$\begin{array}{c}\text { Transtion } \\
\text { variable }\end{array}$} & \multirow{2}{*}{$\begin{array}{l}\text { Regressors } \\
\text { s.t. transition }\end{array}$} & \multicolumn{3}{|c|}{$\mathcal{T}_{1}$} & \multicolumn{3}{|c|}{$\mathcal{T}_{2}$} \\
\hline & & & $K=1$ & $K=2$ & $K=3$ & $K=1$ & $K=2$ & $K=3$ \\
\hline \multirow{5}{*}{$\begin{array}{c}1959-1973 \\
(T=60)\end{array}$} & RTB & RTB & $6.48^{*}$ & $6.33^{*}$ & $5.50^{*}$ & $6.51^{*}$ & $8.58^{*}$ & 7.97 \\
\hline & & RTB, RGDP & $6.49^{*}$ & $6.34^{*}$ & 5.48 & 6.53 & 7.17 & 6.36 \\
\hline & RGDP & RTB, RGDP & 5.35 & 3.50 & 3.12 & 7.52 & 7.67 & 8.52 \\
\hline & & RGDP & 3.17 & 1.26 & 1.09 & 7.28 & 7.10 & 7.32 \\
\hline & RTB, RGDP & RTB, RGDP & 7.02 & 6.41 & 5.48 & 10.8 & 13.4 & 14.4 \\
\hline \multirow{5}{*}{$\begin{array}{c}1977-2000 \\
(T=96)\end{array}$} & RTB & RTB & 0.82 & 0.59 & 0.28 & 0.82 & 0.61 & 0.32 \\
\hline & & RTB, RGDP & 3.32 & 5.55 & 4.53 & 3.94 & 6.65 & 5.13 \\
\hline & RGDP & RTB, RGDP & $10.0^{* *}$ & $14.0^{* *}$ & $9.17^{*}$ & $10.1^{*}$ & $14.1^{* *}$ & $9.21^{*}$ \\
\hline & & RGDP & $9.40^{* *}$ & $13.0^{* *}$ & $8.33^{* *}$ & $9.72^{* *}$ & $13.3^{* *}$ & $8.54^{*}$ \\
\hline & RTB, RGDP & RTB, RGDP & $10.2^{*}$ & $14.2^{* *}$ & $9.22^{*}$ & 10.7 & $14.9^{*}$ & 9.79 \\
\hline
\end{tabular}




\section{$7 \quad$ References}

Andrews, D.W.K. (1991), 'Heteroskedasticity and autocorrelation consistent covariance matrix estimation,' Econometrica, 59, 817-858.

Andrews, D.W.K. (1993), 'Tests for parameter instability and structural change with unknown change point,' Econometrica, 61, 821-856.

Andrews, D.W.K. and W. Ploberger (1994), 'Optimal tests when a nuisance parameter is present only under the alternative,' Econometrica, 62, 1383-1414.

Baba, Y., D. F. Hendry and R. M. Starr (1992), 'The demand for M1 in the U.S.A., 1960-1988,' Review of Economic Studies, 59, 25-61.

Baumol, W.J. (1952), 'The transactions demand for cash: an inventory theoretic approach,' Quarterly Journal of Economics, 66, 545-556.

Goldfeld, S.M. (1976), 'The case of missing money,' Brookings Papers on Economic Activity, 1976:3, 683-739.

Granger, C.W.J. and T. Teräsvirta (1993), Modelling Non-linear Economic Relationships, Oxford University Press, Oxford.

Hansen, B.E. (1992), 'Convergence to stochastic integrals for dependent heterogeneous processes,' Econometric Theory, 8, 489-500.

Hansen, B.E. (1996), 'Inference when a nuisance parameter is not identified under the null hypothesis,' Econometrica, 64, 413-430.

Hendry, D.F. and N.R. Ericsson (1991), 'Modeling the demand for narrow money in the United Kingdom and the United States,' European Economic Review, 35, $833-886$.

Hoffman, D.L. and R.H. Rasche (1991), 'Long-run income and interest elasticities of money demand in the United States,' Review of Economics and Statistics, $78,665-674$.

Hoffman, D.L., R.H. Rasche and M. A. Tieslau (1995), 'The stability of long-run money demand in five industrial countries,' Journal of Monetary Economics, $35,317-339$.

Krugman, P. (1991), 'Target zones and exchange rate dynamics,' Quarterly Journal of Economics, 106, 669-682.

Lütkepohl, H. T. Teräsvirta and J. Wolters (1999), 'Investigating stability and linearity of a German M1 demand function,' Journal of Applied Econometrics, 14, $511-525$.

Luukkonen, R., P. Saikkonen and T. Teräsvirta (1988), 'Testing linearity against smooth transition autoregressive models,' Biometrika, 75, 491-499. 
Meese, R.A. and A.K. Rose (1990), 'Nonlinear, nonparametric, nonessential exchange rate estimation,' American Economic Review, 80, 192-196.

Meese, R.A. and A.K. Rose (1991), 'An empirical assessment of non-linearities in models of exchange rate determination,' Review of Economic Studies, 58, 603619 .

Phillips, P. C. B. and M. Loretan (1991): "Estimating long run economic equilibria,' Review of Economic Studies, 58, 407-436.

Saikkonen, P. (1991), 'Asymptotically efficient estimation of cointegration regressions,' Econometric Theory, 7, 1-21.

Saikkonen, P. and I. Choi (2000), 'Cointegrating smooth transition regressions with application to the Asian currency crisis,' SFB 373 Discussion Paper No. 98, Humboldt University, Berlin.

Stock, J. H. and M. W. Watson (1993), 'A simple estimator of cointegrating vectors in higher order integrated systems,' Econometrica, 61, 783-820.

Teräsvirta, T. (1998), 'Modeling economic relationships with smooth transition regressions,' In A. Ullah and D.E.A. Giles (eds.), Handbook of Applied Economic Statistics, Dekker, New York, pp. 507-552.

Tobin, J. (1956), 'The interest-elasticity of transactions demand for cash,' Review of Economics and Statistics, 38, 241-247.

van Dijk, D., T. Teräsvirta and P. H. Franses (2000), 'Smooth transition autoregressive models - a survey of recent developments,' Econometric Review (forthcoming). 